\title{
The role of badgers in the epidemiology
} of Mycobacterium bovis infection (tuberculosis) in cattle in the United Kingdom and the Republic
of Ireland: current perspectives on control strategies

This article was published in the following Dove Press journal:

Veterinary Medicine: Research and Reports

19 December 2014

Number of times this article has been viewed

\author{
Deirdre Ní Bhuachalla' \\ Leigh AL Corner' \\ Simon J More ${ }^{1,2}$ \\ Eamonn Gormley' \\ 'School of Veterinary Medicine, \\ University College Dublin, Dublin, \\ Ireland; ${ }^{2}$ Centre for Veterinary \\ Epidemiology and Risk Analysis, \\ University College Dublin, Dublin, \\ Ireland
}

\begin{abstract}
Bovine tuberculosis (TB), caused by infection with Mycobacterium bovis, is a persistent problem in cattle herds in Ireland and the United Kingdom, resulting in hardship for affected farmers and substantial ongoing national exchequer expenditure. There is irrefutable scientific evidence that badgers are a reservoir of $M$. bovis infection and are implicated in the transmission of infection to cattle. A range of options for the control of TB in badgers is currently available or under development including culling of badgers, vaccination of badgers and cattle, and improved biosecurity to limit contact between the two species. It is unlikely that the eradication of TB from cattle will be achieved without the reservoir of $M$. bovis infection in badgers being controlled. The chances of success will, however, improve with greater knowledge of the disease in both species and an understanding of the epidemiological drivers of the transmission of infection between badgers and cattle.
\end{abstract}

Keywords: Mycobacterium bovis, badgers, tuberculosis, cattle, vaccination, culling

\section{Introduction}

Mycobacterium bovis is the principal causative agent of tuberculosis (TB) in animals. In countries where the disease remains uncontrolled in livestock, it can result in reduced productivity and lifespan with severe economic implications for the affected farms, and it also poses a zoonotic risk. ${ }^{1}$ In developed countries, the application of comprehensive test and slaughter campaigns has served to reduce the incidence of TB in national herds to the extent that it has been either eradicated or the incidence substantially reduced. ${ }^{2}$ Statutory control and eradication programs have been operating in the Republic of Ireland (ROI) and in the UK since the 1950s. ${ }^{3,4}$ Under the relevant EU legislation (64/432 EEC and 78/52 EEC), the frequency of routine surveillance is determined by the prevalence of infected herds, and this varies between countries. Annual herd testing has been conducted in the ROI since the commencement of the eradication program in 1954, in Northern Ireland (NI) since 1982 and in Wales since October 2008. More recently in Wales, 6 month herd testing has been carried out in areas with highest incidence rates of bovine TB (intensive action areas [IAAs]). For the purpose of bovine TB control in England, the landmass is divided into a high risk area (HRA), low risk area (LRA) and a buffer zone (edge area) that lies between the HRA and LRA. Annual testing is conducted in the HRA and the buffer areas and quadrennial testing is conducted in the LRA. In Scotland, which has been officially TB-free since 2009, quadrennial
Correspondence: Eamonn Gormley School of Veterinary Medicine, Veterinary Sciences Centre, University College Dublin (UCD), Belfield, Dublin 4, Ireland Tel +353 | 716 6073

$\mathrm{Fax}+353$ । 7166090

Email egormley@ucd.ie 
herd testing had been ongoing for at least 10 years and since 2012 some low-risk herds have been exempt from testing.

The principal components of the eradication program in most countries are surveillance testing of herds with the single intradermal tuberculin test or the single intradermal cervical comparative tuberculin test with the option of additional diagnostic testing in diseased herds supplemented with the interferon- $\gamma$ (IFN- $\gamma$ ) assay. The programs also include compensation for the loss of reactor animals and lost production, and a range of controls to minimize the risk of the movement of infected cattle from affected herds. Diagnostic testing is focused on infected herds, on contiguous neighboring herds considered at-risk, on herds identified from routine slaughter monitoring, and on herds identified at risk from contact tracing of animals. The costs of running the national programs are substantial, with costs in Great Britain in 2010/2011 exceeding £152 (€190) million, £23 (€29) million in NI, and $€ 63$ (£50) million in the ROI. ${ }^{5}$

Although compulsory state-sponsored programs have achieved eradication of TB from cattle in many EU member states, ${ }^{6}$ not all have been successful. In the UK and the ROI, animal-level apparent prevalence was reduced to less than $1 \%$ by the mid- $1960 \mathrm{~s}^{7-9}$ and to a mean of $0.4 \%$ by $2010 .^{5}$ However, the goal of eradication has remained elusive $e^{4,5}$ and the ROI and parts of the UK have the highest levels of TB in Europe. ${ }^{6}$ A recent study employing standardized definitions and measures to identify demographic features and trends in TB in cattle between 1995 and 2010 in the UK and ROI showed a reducing prevalence in the ROI and, up to 2009 , a rising trend in England, Wales, and NI. It confirmed a stable situation of extremely low prevalence in Scotland. ${ }^{5}$

Although cattle (Bos taurus and Bos indicus) worldwide are the principal hosts for $M$. bovis, other species of domestic and wild animals may act as reservoirs of infection. ${ }^{10}$ These have posed an obstacle to eradication of TB from cattle due to onward transmission. In wildlife, the epidemiology of TB differs with the species affected and their environment. Infected wildlife populations can be classed as maintenance hosts when infection persists by intra-species transmission, and spillover hosts where infection does not persist indefinitely without re-infection from another host species. Examples of wild animal species that act as maintenance hosts and are capable of infecting cattle and other spillover species include the European badger (Meles meles) in the UK and the ROI, the European wild boar in Spain (Sus scrofa scrofa), the brushtail possum (Trichosurus vulpecula) in New Zealand, the white-tailed deer (Odocoileus virginianus) in
North America, the African buffalo (Syncerus caffer) in South Africa, and the lechwe antelope (Kobus leche) in Zambia. The presence of TB in these species has to varying degrees hindered the control and eradication of TB in associated cattle populations. ${ }^{8,11-13}$

M. bovis infection was first identified in badgers in the south-west of England in $1971^{14}$ and in the ROI in 1974, ${ }^{15}$ however, the significance of these findings was not fully appreciated at the time. In more recent times, TB has been reported in badgers in Spain ${ }^{16}$ and France. ${ }^{17} \mathrm{~TB}$ is endemic in the badger populations in the ROI and parts of the UK where they contribute to the spread and persistence of infection in associated cattle populations. ${ }^{18-21}$ There is no mandatory requirement for TB surveillance of wildlife under EU legislation, however, prevalence estimates have been determined by detailed research studies. The prevalence of TB in badgers in the ROI is not uniform and a prevalence of $36.3 \%$ was reported in areas where there is high prevalence of bovine TB based on detailed postmortem, histopathology, and bacteriology. ${ }^{22,23}$ In areas with a low prevalence of bovine TB, the prevalence of TB in badgers determined using equivalent postmortem examination was $14.9 \% .{ }^{24}$ In the UK, estimates of prevalence in badgers vary widely $(1.6 \%-37.2 \%)$ depending on the postmortem and culture methods used. ${ }^{25}$

In studies conducted in the ROI, the molecular genotyping of isolates of $M$. bovis by restriction fragment length polymorphism revealed that the most prevalent restriction fragment length polymorphism types were widely distributed and present in both cattle and badgers. The molecular epidemiology of relationships between strains revealed that badgers and cattle tended to have similar strains, consistent with the sharing of $M$. bovis strains within an area providing evidence of cross-species transmission. ${ }^{26,27}$ Whereas the control strategies for dealing with TB in cattle populations are well established, the transmission of infection from wildlife reservoirs poses particular challenges. As both badgers and cattle are maintenance hosts and the epidemiology of infection in these two species is interdependent it is likely that the eradication of TB from cattle cannot be achieved without effective management of the disease in the badger population. ${ }^{28}$ Control and eradication of infection requires a detailed understanding of the pathogenesis and epidemiology of TB in both species. With this knowledge, effective strategies can be devised to break the transmission of infection between the species. Here, we review the current knowledge on TB in European badgers in the UK and ROI and discuss the different strategies being developed to control infection. 


\section{Badgers and TB}

The ecology and social behavior of the badger is important in facilitating interactions with cattle, and when the badger is infected with TB, these interactions may lead to a risk of transmission. Badgers are territorial nocturnal mammals living in social groups in underground setts that are located throughout their territory. ${ }^{29}$ In areas of high population density, as for example in the south-west of England, social groups may consist of eight to 20 individuals of mixed age and sex. ${ }^{30}$ In medium and low density areas, as in the ROI, social groups are smaller, with 2.5 to three individuals per social group. ${ }^{31}$ Irrespective of the density of social groups, there is a constant level of intergroup contact and defense of territory may lead to high levels of intergroup aggression. Badgers are generalist foragers with diverse dietary preferences that may include invertebrates, insects, amphibians, small mammals and carrion, as well as cereals, fruit, and vegetation. ${ }^{32,33}$ In parts of their range, they show highly specialized feeding behaviors, such as in the south-west of England where the diet is composed predominantly of earthworms. ${ }^{34}$ Where pastures are rich in food resources, the presence of feeding badgers will increase the likelihood of contact between badgers and cattle sharing the same local environment. ${ }^{35}$ In addition, during periods of food scarcity, badgers may supplement their diet with cattle feed. This attraction to locations where cattle are housed and the subsequent risk of close interaction between the two species may be an important component in the transmission cycle of infection between badgers and cattle.

\section{Pathology}

TB in badgers is primarily a chronic respiratory disease with dissemination to other organ systems as the infection progresses. ${ }^{23,36-38}$ Where the infection causes death it is frequently associated with advanced lung disease. ${ }^{37} \mathrm{In}$ naturally infected populations, there is a wide spectrum in disease severity from latent subclinical infection with no visible lesions or clinical signs of disease, through mild disease with small pulmonary and extra-pulmonary lesions, to severe disease with generalized pathology leading to death. Although badgers are very susceptible to infection, within a population infection is most frequently seen in its latent form with only a small proportion of badgers progressing to disseminated disease. ${ }^{23,39}$ Murphy et $\mathrm{al}^{23}$ (2010) examined badgers $(\mathrm{n}=215)$ from a wide geographical distribution in the ROI and reported that two thirds $(66.7 \%)$ of infected badgers had no visible lesions. Gallagher and Clifton-Hadley ${ }^{37}$ (2000) reported similar results in the UK with $33 \%-80 \%$ of infected badgers having no visible lesions.

M. bovis enters the host principally by the inhalation of infectious aerosol particles, which are taken up by lung alveolar macrophages. Dissemination of infection from the lungs occurs via the lymphatics to the bronchial-associated lymph nodes and into the circulatory system. ${ }^{40} \mathrm{~TB}$ is an immuno-pathological disease where the formation of lesions results from the specific immune response to the presence of M. bovis. There is evidence that tuberculous lesions in badgers may resolve ${ }^{37,41}$ although the mechanism for achieving this is not understood. Badgers can also be co-infected with more than one strain. ${ }^{22}$

\section{Epidemiology of TB transmission}

Badgers are an ideal host for $M$. bovis because infection in populations is endemic, the disease kills few badgers and their deaths do not significantly perturb population density nor the size and structure of social groups. Infected badgers may survive for long periods with the disease and tuberculous females may produce cubs. ${ }^{42}$ Especially significant in facilitating aerosol transmission is the close contact that occurs between badgers within the subterranean environment of the sett, during sleeping and also during grooming. Transmission from dam to cub by pseudo-vertical transmission via the respiratory route during the rearing phase rather than in utero transmission is considered a significant route of transmission and may be a key factor in maintenance of infection within local populations..$^{42}$

Although urinary excretion of M. bovis is often cited as a dominant transmission route, renal lesions are infrequently detected in naturally infected badgers. ${ }^{39,43}$ In infected badgers the concentration of bacilli in infected tissues varies widely from 1-2 colony forming units (CFU)/g in latently infected badgers to greater than $10^{5} \mathrm{CFU} / \mathrm{g}$ in the tissues and exudates of terminally-ill animals. The level and route of M. bovis excretion is determined by the site and severity of lesions. Excretion is most common from the respiratory tract and from skin lesions, infrequently from the urinary tract, even less frequently from the digestive tract. ${ }^{39,41}$ Respiratory excretion is in the form of aerosol particles or as sputum. When infectious sputum is swallowed, M. bovis may appear in the feces. Excretion in most infected badgers is difficult to detect, as there are low numbers of bacilli in exudates. Few badgers have disease that is sufficiently advanced to provide the high concentration of $M$. bovis in excreta needed to initiate infection by ingestion. However, although badgers with advanced or terminal disease constitute a very small 
proportion of infected badgers, their excreta may contain very high concentrations of bacilli with maximal concentrations reported of $10^{5}-10^{6} \mathrm{CFU} / \mathrm{mL}$ in bronchial exudates, $10^{2}-10^{5} \mathrm{CFU} / \mathrm{mL}$ in urine, and $10^{2}-10^{5} \mathrm{CFU} / \mathrm{g}$ in feces. It is notable that all the badgers with high levels of fecal excretion had visible pulmonary lesions. ${ }^{44}$

The risk of transmission from tuberculous badgers to cattle arises from a combination of the prevalence of infection in the badger population, the stage of disease in the badgers, the routes and levels of excretion from the infected badgers, the routes of exposure of the cattle, and minimum infective dose (MID) for each of the infection routes. There are two possible routes of transmission from infectious badgers to cattle: 1) by infectious aerosol, and 2) by ingestion of food contaminated with infectious badger excreta or wound discharge. The high prevalence of lung lesions and the demonstration by culture of infection in the lungs of badgers and cattle all strongly support the lungs as the principal site of primary infection and excretion, and that inhalation of infectious aerosol particles is the principal mode of transmission..$^{36,37,39,41,45}$ The MID by the respiratory route is probably as low as 1 bacillus for all susceptible species. ${ }^{46-48}$ The MID for bite wound transmission is also in the order of 1 bacillus. The MID is likely to be much higher for initiation of infection in the upper respiratory tract or in the gastrointestinal tract following ingestion of contaminated food. The low infective dose for transmission to the lower lung makes aerosol transmission much more achievable than by ingestion. Although direct contact between cattle and badgers appears to occur infrequently, where there is a high prevalence of infection in badgers, transmission from badgers to cattle can occur. Furthermore, when badgers are terminally-ill due to TB, behavioral changes may occur, which increases the risk of direct contact between the infectious badgers and cattle and the risk is compounded by the higher level of respiratory excretion. ${ }^{49}$ The predominant direction of transmission is from badgers to cattle. Where regular testing of cattle is conducted and advanced disease cases become rare, the risk of cattle to badger transmission will be less than in situations where infrequent testing takes place and advanced clinical cases are more common. In contrast, where there are no programs in place to control the disease in badgers, the risk of badger to cattle transmission increases due to the proportion of badgers with advanced disease.

For aerosol transmission of infection to occur, there must be close contact between the infectious animal and the susceptible animal and the risk only lasts a very short time before the aerosol is dispersed or the bacilli killed by environmental factors. ${ }^{50}$ Where the aerosol contains a low concentration of infectious particles, the aerosol concentration quickly becomes diluted as it travels away from the source such that the majority of transmission only occurs in the immediate vicinity of the source. Transmission by routes other than aerosol, that is via $M$. bovis excreted in feces, urine, sputum, and wound exudates, is only possible if the pathogen survives in the environment at a sufficiently high concentration for a period of time after excretion to allow for uptake by the susceptible host. ${ }^{51}$ The survival of the pathogen depends on a range of physical, biological, and environmental factors, including damage to the bacterial cell during the droplet formation, the rapidity of desiccation and rehydration, temperature, relative humidity, ultraviolet light, ionizing radiation, open air factor, air ions, and pollutants. ${ }^{51-55}$

\section{Options for control of TB in badgers and cattle}

Following the roll-out of eradication schemes in the ROI and the UK in the 1950s, the regular testing of cattle substantially reduced the incidence of cattle-cattle transmission. However, eradication was not achieved and this has often been blamed on the imperfect nature of available diagnostic tests. However, many other countries have achieved eradication through cattle testing alone. Since badgers were first identified as a host for $M$. bovis over 40 years ago, various options have been explored to manage TB in badger populations. The objective of the control strategies is to reduce the contact rate and the risk of transmission of infection between badgers and cattle. The strategies include culling of badgers, improved biosecurity measures to separate the two species, and vaccination to reduce the proportion of the population that is susceptible to infection. However, these options are often constrained for economic, conservation, social reasons or the unavailability of a vaccine. The badger is a legally protected species under legislation in the ROI (Wildlife Act, 1976) and in the UK (Protection of Badgers Act, 1992). Under the Bern Convention on the Conservation of European Wildlife and Natural Habitats, badgers are listed as protected. However, there is a derogation allowing for culling of badgers as part of the bovine TB control and eradication program.

\section{Culling of wildlife}

Culling of wildlife species as a disease management strategy is complex and raises numerous epidemiological, ethical, and political issues. The main objective of culling is to reduce the size of the reservoir population thereby limiting the risk of transmission of $M$. bovis within the wild animal 
species and spread to other wildlife and livestock. Culling may be selective, with operations limited to known infected populations or infected individuals within populations. Non-selective culling can be applied to populations without regard to infection status on the assumption that a decreased population size and density will decrease transmission risk. Culling of infected wild animal populations has contributed to the success of TB control and eradication programs in a number of countries. In Australia, the eradication of diseased populations of feral Asian water buffalo (Bubalus bubalis) and feral cattle contributed to the successful eradication of TB from domestic cattle. ${ }^{56}$ In New Zealand, the aggressive and sustained reduction of brushtail possum populations has been correlated with the reduced incidence of TB in domestic cattle and deer herds. ${ }^{57,58,59}$ In Minnesota in 2006, during a large bovine TB outbreak, $M$. bovis infected white-tailed deer were identified as being linked to infection in cattle. Reduction of the deer population was considered an important control strategy and was achieved through focused culling, an extension of the hunting season, and an increase in the availability of permits for landowners to harvest deer. ${ }^{60}$ This contributed to the successful eradication of TB from cattle in Minnesota and no incidence cases in either species has been detected since 2008 .

Much of the evidence for the role of badgers in the transmission of TB to cattle comes from culling studies and badger removal operations conducted over the last 30 years in the ROI and the UK. These results collectively point to the conclusion that badgers contribute to the epidemiology of TB in cattle and have also helped identify various control strategies that might be employed to limit the transmission rates between badgers and cattle.

\section{Culling of badgers: ROI}

The rationale for the strategy is to reduce badger population densities in selected areas and minimize the risk of contact between cattle and infected badgers. A number of controlled badger culling studies have been conducted in the ROI to better understand the significance of badgers in TB epidemiology in cattle. Two controlled badger culling studies (East Offaly Project and the Four Area Study) confirmed that badgers contributed to the epidemiology of TB in cattle by demonstrating a significant drop in TB prevalence in cattle herds in areas that were proactively culled in comparison to the control areas. ${ }^{18,61}$ A further study in Laois between 1989-2005 was conducted to assess culling as it is undertaken in the ROI and the results provided evidence that culling had a positive impact on the risk of future breakdowns and a positive protective effect on herds neighboring the index herd. ${ }^{62}$ Badger culling was incorporated into the national TB eradication strategy in the ROI in 2004. The current targeted culling program aims to reduce the local population of badgers from a starting density of $\geq 2$ badgers per $\mathrm{km}^{2}$ to within the range of $0.2-0.5$ badgers per $\mathrm{km}^{2}$ resulting in significant reduction in badger density. ${ }^{63}$ The total badger population of the ROI is estimated to be $84,000 .{ }^{64}$ Between 5,000 and 6,000 badgers are removed annually. Culling is initially reactive, targeting badger setts within $1-2 \mathrm{~km}$ of a breakdown herd and where a veterinary epidemiological investigation has excluded the introduction from purchased cattle, spread from neighboring properties or residual infection within the herd, and where badgers are identified as a probable source of infection. ${ }^{65}$ Subsequently, culling is conducted proactively and targets an area up to $2 \mathrm{~km}$ from the farm boundary. The culling is focused on areas of high disease prevalence in cattle and in these areas there is also a high disease prevalence in badgers. ${ }^{23,24}$ Currently, badgers are culled on $28 \%$ of the national area of agricultural land in ROI with an upper limit permitted of $30 \%$ of the national area of agricultural land to comply with licensed regulations. The culling is conducted under licenses granted by the National Parks and Wildlife Service of the Department of the Arts, Heritage and the Gaeltacht. In contrast to reports from the UK there is no evidence in the ROI that the removal of badgers has led to an increase in herd TB breakdowns, either during or following a period of proactive culling ${ }^{61,66,67}$ or on land surrounding areas of proactive culling. ${ }^{67}$ There is however, field-based evidence in support of targeted badger removal as an effective method to minimize badger-to-cattle transmission. ${ }^{62}$ In the last 50 years the ROI has succeeded in decreasing TB incidence in cattle and maintaining it at a relatively low level. This has been achieved using a program of sustained cattle testing and targeted badger culling. At the end of $2011,97.8 \%$ of cattle herds were officially TB free, and during $2011,99.68 \%$ of animals were TB free. ${ }^{68}$

\section{Culling of badgers: UK}

The study that had the greatest impact on UK government policy on badger culling was the Randomized Badger Culling trial (RBCT) conducted between 1998 and 2005. ${ }^{69}$ The trial had ten triplicate areas, each approximately $100 \mathrm{~km}^{2}$. In each triplet, there was a non-cull, reactive cull, and proactive cull area. When areas with proactive culling were compared to non-culled areas, there was a $19 \%$ reduction in the incidence of confirmed cattle herd breakdowns. A 2011 report showed that from the commencement of culling to 5 years after the last cull, there was a $28 \%$ reduction in confirmed herd 
incidence in the proactively culled areas compared with the non-cull areas. ${ }^{70}$ An increase of $22 \%$ in confirmed cattle herd breakdown was observed in the areas surrounding the proactive culling areas. ${ }^{21}$ This "edge effect" was not observed in the RBCT post-trial period ${ }^{71}$ and has not been seen in association with culling in the ROI. "Social perturbation", the disruption of badger social groupings that can lead to increased badger movement and increased contact between social groups and an increased risk of badger-to-badger and badger-to-cattle transmission, was blamed for the earlier increase. The reactive culling component of the RBCT was never completed, being prematurely suspended in 2003 when the incidence of cattle TB in non-cull areas increased by $27 \%$ compared to the reactive cull areas. ${ }^{19}$

In 2011, the Department for Environment, Food \& Rural Affairs announced that badger culling would be permitted as part of a badger control managed policy. Licenses were issued by Natural England (under the Protection of Badgers Act 1992) that enabled groups of farmers and landowners in the worst affected areas of England to reduce badger populations for the purpose of preventing the spread of disease to cattle. A trial of the policy was conducted with the aim of confirming assumptions of the effectiveness of badger removal, humaneness, and the safety of culling by shooting free-moving badgers. Culling commenced in Somerset in late August 2013 and in Gloucestershire in September 2013 with the goal of removing at least $70 \%$ of the estimated population of badgers in each area over a 6 week period. The target figures were not achieved and the trials were suspended.

\section{Biosecurity measures}

When sharing the same environment, there are probably frequent opportunities for contact between livestock and infectious badgers, either by direct (ie, close) contact, or indirectly through contact with infectious excreta. ${ }^{72}$ Although it is important to reduce all risks wherever possible, direct contact between badgers and cattle may be easier to manage than indirect contact, and all contacts in buildings easier to manage than contact at pasture. Biosecurity measures employed around farm buildings focus on preventing contact between cattle and badgers and badger excreta; that is, the aim is to exclude badgers from both feed stores and cattle pens. It has been shown that badgers may be regular visitors to buildings on farms. In one Gloucestershire study, 19 of 32 farms were visited by badgers at least once each year and some with great frequency. On three of the farms they visited more than $60 \%$ of nights. ${ }^{73}$ Some simple exclusion methods, such as metal-sheeted gates and fences, retractable electric fencing and secured feed bins, are effective in preventing badger access to buildings. ${ }^{73}$

Compared with the exclusion of badgers from buildings, biosecurity measures for pastures are more problematic and less effective in preventing either direct or indirect contact between the species or contamination of cattle feed. However, prevention measures to reduce contact between the species at pasture may be less important, as interactions between badgers and cattle at pasture are infrequent and badgers prefer to maintain a minimum distance of 2-3 m from cattle. ${ }^{74,75}$ Nonetheless, some individual badgers do have high contact rates ${ }^{75}$ and if infectious, could act as a source for the spread of infection. Grazing cattle strongly avoid feed contaminated with feces or urine. ${ }^{76}$ Badger latrines are likely to present the greatest risks of $M$. bovis transmission to cattle at pasture, however, cattle are not particularly attracted to badger latrines. ${ }^{76}$

Although these studies have focused on the frequency of badger visits and contact with cattle, no field trial has been conducted demonstrating a sustained reduction in cattle TB incidence as a consequence of biosecurity measures alone. Additionally, there is reluctance by some farmers to invest in barriers to reduce contact between badgers and livestock as they are impractical, expensive, and it is unlikely that they will be $100 \%$ effective in the face of high risk of exposure of infection from high prevalence badger populations, and where the potential for interactions with cattle is high.

\section{Vaccination as a control strategy in badgers}

The development of a TB vaccine is a key component in the development of new strategies for the control and eradication of TB from badgers and vaccination may play a role in the control of TB in cattle. ${ }^{28} \mathrm{~A}$ vaccine based on the live, avirulent $M$. bovis strain bacillus Calmette-Guerin (BCG), has been used in badgers and cattle studies. The BCG vaccine is currently the only vaccine licensed for use against TB in humans and has been shown to provide protection in both captive and wild badgers. ${ }^{77-80}$ It is effective in generating a protective response in captive badgers when delivered by the parenteral (subcutaneous and intramuscular) or mucosal (conjunctival and oral) routes. ${ }^{77,79-81}$ The BCG vaccine has also been shown to be safe when administered parenterally to captive and wild badgers. ${ }^{82}$ An effective vaccine would prevent infection occurring, as has been reported in brushtail possums,${ }^{83}$ or change the expression of the disease and limit the rate of $M$. bovis excretion, as reported in captive badger studies. ${ }^{81}$ At the population level, the vaccine would be used to reduce the prevalence of infection in the badger popula- 
tion or to provide a barrier to the geographic expansion of endemic areas. Vaccination of badgers could be used alone and so remove the requirement for culling, or in conjunction with culling. ${ }^{84}$ The control of TB in badgers would enhance the effectiveness of control measures in cattle by removing the risk of re-infection from badgers.

\section{Vaccination in ROI}

In the ROI a 3 year field trial has been conducted to assess the impact of oral lipid-encapsulated BCG vaccination of badgers on disease levels in the badger population. ${ }^{85}$ The field trial used an oral BCG vaccine (Immune Solutions Ltd, Otago, New Zealand) because oral vaccination will probably be the method of choice for a broad-scale mass vaccination of free-range badger populations. The field trial was designed with three principal objectives: 1) to validate the results of captive badger studies, 2) to determine if oral vaccine is protective in naturally exposed wild badgers, and 3) to estimate vaccine efficacy. In the double blind trial, different proportions $(0 \%, 50 \%$, and $100 \%)$ of the badger population were vaccinated using either BCG-Danish or placebo. The design allowed for estimation of both the direct vaccine efficacy and indirect effects (herd immunity). The secondary objectives were to measure the effect of BCG vaccination in badgers with pre-existing $M$. bovis infection, and generate practical experience on the logistics of oral vaccine delivery to wild badger populations. The trial analysis is due to be completed in 2015.

\section{Vaccination in the UK}

An injectable BCG vaccine was granted a license for use in the UK in 2010. Although no formal scientific field trial has been conducted to estimate the efficacy of this BCG vaccine in the UK there have been several related studies. In a safety trial of the injectable vaccine in wild badgers in England, a 74\% decrease in the risk of sero-conversion was demonstrated, ${ }^{79}$ as was a positive indirect effect on the risk of disease in cubs in vaccinated social groups. ${ }^{80}$ The success of that field study led to a study on the implementation of badger vaccination, the Badger Vaccine Deployment Project. ${ }^{86}$ The study involves trapping and vaccination of badgers by intra-muscular injection of BCG in a $100 \mathrm{~km}^{2}$ area in Gloucestershire. The aims of the project, which is ongoing, are to provide training for vaccinators and to examine the logistics and costs of deploying an injectable vaccine. In September 2014, the Department for Environment, Food \& Rural Affairs announced a Badger Edge Vaccination Scheme ${ }^{87}$ Vaccination will be conducted on a voluntary basis and groups will be offered up to $50 \%$ funding for costs of the vaccination. The aim is to create a "buffer zone" and prevent further spread of TB through the edge area from the HRA to the LRA.

Although the injectable BCG vaccine is available and is being used, it is unlikely that it would be practical in a widescale vaccine strategy. For that purpose, an oral vaccine would probably be the more cost-effective option. The optimal oral vaccine would be contained in bait that is attractive and palatable to badgers and compatible with live BCG. Several bait formulations are under consideration. Further, field studies to investigate levels of uptake of candidate baits in wild badger populations have been undertaken in the UK and ROI. 88,89

In 2012 the Welsh Government embarked on a 5 year enhanced TB control program that incorporated badger vaccination using the injectable $B C G$ vaccine. This project is being conducted within the bovine TB IAA and a range of measures has been introduced to reduce or eliminate TB from all affected species within the area. The IAA covers approximately $200 \mathrm{~km}^{2}$ and is located in an area of endemic bovine TB. One objective of the strategy is to vaccinate as many badgers as possible over 5 years within the IAA. The assessment of the vaccination strategy will measure the impact on cattle herd breakdowns. Vaccination forms only part of the strategy in the IAA with additional control measures including enhanced cattle surveillance, improved biosecurity measures, and surveillance of non-bovine hosts for TB (goats and camelids) also being carried out. ${ }^{90}$

Recently, the Department of Agriculture and Rural Development in Northern Ireland commenced a "test and vaccinate or remove" strategy. This study will focus on removing diseased badgers while protecting uninfected animals and avoiding killing presumed TB-free badgers. Badgers will be trapped, tested with a serological assay, and then the test negative badgers will be vaccinated and released or the test positive animals will be removed. The trial will assess changes in cattle herd incidence rates in vaccine areas compared with those in a matched control area. ${ }^{84}$

\section{Choice of strategy}

No single strategy for vaccine delivery will be suitable for control of infection in all populations of badgers and a number of different options will need to be considered to optimize the chances of vaccine success. The choice of vaccination strategy will require an understanding of how the vaccine performs in the different populations. The objective of each strategy would be to reduce or remove the risk of transmission from badgers to cattle. ${ }^{28}$ Broad-scale vaccination programs would be conducted on a long-term basis as 
infected animals will continue to exist in the vaccinated population and surrounding areas, and continue to act as a potential source of re-infection. If eradication of TB from badgers is the objective of the program, as opposed to only decreasing the risk of transmission to cattle, then uniform vaccination of the entire population, or a significant proportion of it, will need to continue until the last infected badger dies or is otherwise removed. Although undisturbed badger populations turn over at a more or less constant rate with an average life expectancy of 3-4 years, some individuals, both M. bovis-infected and non-infected animals live for many more years, as mortality rates due to TB are relatively low. It is the lifespan of infected animals that will determine the length of time that vaccination must continue.

\section{Vaccination as a control strategy in cattle}

The vaccination of cattle has often been promoted in the UK as a logical and feasible approach to the control of TB in cattle. The BCG vaccine is effective at protecting individual cattle after experimental and natural $M$. bovis challenge. ${ }^{91}$ Vaccine studies in herds naturally exposed to $M$. bovis infection have been conducted in Ethiopia and Mexico and the levels of protective efficacy measured were $56 \%-68 \%$ and $59.4 \%$, respectively. ${ }^{92,93}$

Notwithstanding these positive results and the demands to introduce vaccination in the UK, there are significant hurdles to overcome before cattle vaccination could be incorporated into an eradication program. Vaccination of cattle against TB is explicitly forbidden under EU legislation on disease control (Council Directive 78/52/EEC) and in intra-Union trade legislation. In addition, vaccination is not compatible with accepted cattle diagnostic testing or the herd classification system (Council Directive 64/432/EEC). One of the principal reasons for the ban on cattle vaccination is the possibility that vaccinated animals will not be sufficiently protected against TB exposure to prevent infection. Due to the imperfect levels of protection generated by the BCG vaccine, vaccinated animals may become infected if exposed to $M$. bovis and then spread the disease. An additional problem is that these vaccinatedinfected cattle cannot currently be accurately distinguished from the non-infected vaccinated animals, due to the interference of vaccination with the existing diagnostic tests (purified protein derivative-tuberculin skin test). This interference has prompted research in the UK into new diagnostic tests to detect infected vaccinated animals (DIVA). The DIVA test uses antigens that are expressed and/or secreted by $M$. bovis field strains but not by the BCG vaccine strain or in almost all environmental mycobacteria. ${ }^{94-97}$ The antigens commonly used are the mycobacterial proteins ESAT- 6 and CFP-10 or peptides derived thereof, and are used in the IFN- $\gamma$ assay to increase the test specificity. An additional antigen, Rv3615c can be included in the test to increase test sensitivity. This antigen, the gene for which is present in both BCG and $M$. bovis, has been shown to stimulate IFN- $\gamma$ responses in a significant proportion of $M$. bovis-infected cattle but not in naïve or BCG-vaccinated animals. ${ }^{98}$ This same antigen can stimulate IFN- $\gamma$ responses in a significant proportion of infected cattle that do not respond to ESAT-6 and CFP-10. Therefore, inclusion of Rv3615c or its functional epitope in combination with ESAT-6 and CFP-10 has the potential to significantly increase sensitivity without reducing specificity in BCG-vaccinated populations. Vaccinated and non-infected animals should give a negative result in the DIVA test, but infected animals should still be detected, independently of their vaccination status.

There are still many unknowns about the performance of the BCG vaccine in large cohorts of cattle naturally exposed to $M$. bovis challenge. Key issues that require further study relate to the level and duration of $\mathrm{BCG}$ protection, the safety risk of shedding of the BCG in milk, and the schedule for vaccination (age of animals, type of herd, frequency of re-vaccination). Another issue relates to the capacity of BCG vaccination to aid in the eradication of TB when applied alongside the existing control measures. The performance of the DIVA diagnostic test in vaccinated herds undergoing routine surveillance testing has not been validated. For example, there is a lack of knowledge on the minimum time between natural infection of cattle with $M$. bovis and the detection of infection in these animals using a DIVA test. In natural infected field animals the timing and infective dose of $M$. bovis challenge is always an unknown, and the immune responses detected by the DIVA test may differ from those measured during experimental infection.

The European Food Standards Authority published its opinion on cattle TB vaccination for the European Commission in December, 2013 and large-scale field trials were proposed to determine vaccine efficacy and to validate a DIVA test. ${ }^{99}$ Subsequently, the European Commission presented a provisional timetable for this research and for the introduction of TB vaccination in cattle in the UK and EU.

\section{Lessons from the Australian and New Zealand TB control and eradication programs}

Although TB in wildlife may be a major constraint to eradication of infection in cattle, some countries have succeeded in 
controlling TB in livestock in the presence of infection in wild animals. Eradication of TB from feral cattle and feral Asian water buffalo (B. bubalis) was a critical part of the Australian eradication program. By 1992, Australia had reached the stage of having no known infected cattle herds, but it was not until 1997 that TB freedom was declared and it was in 2002 when the last infected animals were detected. Likewise, New Zealand has achieved World Organisation for Animal Health TB-free status for domestic livestock in part through culling of the brushtail possum. At its worst, approximately $40 \%$ of New Zealand land area contained populations of tuberculous possums. By culling the possums, the TB herd prevalence declined from $3.6 \%$ in $1992 / 93$ to $0.18 \%$ in $2011 / 12 .{ }^{100}$

When dealing with TB control in cattle in parallel with wildlife control measures, the cattle component of the Australian and the New Zealand programs relied on several key features: the detection of infected animals using the tuberculin skin test (either the single intradermal tuberculin test or the single intradermal cervical comparative tuberculin test), recognition of the low sensitivity and high specificity of the skin test, the control of the movement of animals from infected herds and having the cattle herd as the unit of interest, and only allowing unrestricted movements of cattle from TB-free herds.

The success of the Australian and NZ programs can serve to inform the management strategies in the ROI and the UK, and also other countries dealing with a wildlife reservoir of M. bovis. Most importantly, it highlights that the disease can only be eradicated in cattle after dealing with the wildlife reservoir. The ultimate aim of the badger control programs is to reduce the risk of spread of TB infection to cattle. However, there is still a paucity of information on many aspects of badger-to-cattle transmission of TB and thus the time-scale for when badger control measures will fully impact on animal or herd breakdown rates is uncertain. It is probable that whatever strategies are employed, the decline in the disease prevalence in badgers will be slow and the decline in herd breakdowns will be gradual. It may take some years to see a consequential reduction in herd breakdown incidence resulting from different badger control measures.

\section{Conclusion}

Under the existing EU legislative framework, the current TB eradication programs implemented in the UK and ROI are focused on reducing and eradicating the disease from cattle. However, there are complex relationships between $M$. bovis infection in badgers and cattle and any strategy devised to control the disease of badgers could end up having both beneficial and detrimental effects on the incidence of TB in cattle. Media coverage of badgers and cattle is notable for its focus on badgers and the consequences for TB control in both species arising from culling. Less attention is focused on other potential factors involved in the spread and maintenance of the disease such as cattle movement, the quality of the testing programs, or the role of the farmer in improving the biosecurity risk to the herd. Nevertheless, the development of badger disease control measures, coupled with improvements in the cattle disease program and enhanced biosecurity measures, will facilitate continued progress in reducing infection levels in both species. Success will be dependent on reducing the level of infection in the badger population, but given the reluctance of the public to support large scale culling, especially in the UK, it is likely that vaccination will be the only strategic option available in the long-term. As a disease control strategy, vaccination of badgers would address conservation concerns and the potential detrimental ecological effects of culling. ${ }^{101}$ However, there remains a knowledge gap on many aspects of the epidemiology of disease in cattle and badgers. The contrasting trends of TB in the different countries of the UK and ROI suggest that either the epidemiological drivers of disease are different in each case or that aspects of the respective control and management programs are not optimized. With the availability of a standard methodology to objectively measure progress toward eradication in each country, it may be prudent to review the epidemiological basis of the programs to ensure they are fit for purpose and designed to eradicate TB by taking into account all available scientific information and adequately addressing all known risk factors. Should a clearer epidemiological picture emerge, additional measures may need to be incorporated into the programs that address all sources of infection. Significant progress should then be possible and TB eradication may be achieved.

\section{Acknowledgments}

The research carried out by the authors at UCD on control of TB in cattle and wildlife is supported by funding from the Irish Department of Agriculture, Food and the Marine.

\section{Disclosure}

The authors report no conflicts of interest in this work.

\section{References}

1. Cosivi O, Grange JM, Daborn CJ, et al. Zoonotic tuberculosis due to Mycobacterium bovis in developing countries. Emerg Infect Dis. 1998;4(1):59-70.

2. Collins JD. Tuberculosis in cattle: strategic planning for the future. Vet Microbiol. 2006;112(2-4):369-381 
3. Krebs JR, Anderson R, Clutton-Brock T, Morrison I, Young D, Donnelly CA. Bovine Tuberculosis in cattle and badgers. In: London: MAFF Publications, PB3423; 1997:191.

4. More SJ. What is needed to eradicate bovine tuberculosis successfully: An Ireland perspective. Vet J. 2009;180(3):275-278.

5. Abernethy DA, Upton P, Higgins IM, et al. Bovine tuberculosis trends in the UK and the Republic of Ireland, 1995-2010. Vet Rec. 2014;172(12):312.

6. Reviriego Gordejo FJ, Vermeersch JP. Towards eradication of bovine tuberculosis in the European Union. Vet Microbiol. 2006; 112(2-4):101-109.

7. Abernethy DA, Denny GO, Menzies FD, McGuckian P, Honhold N, Roberts AR. The Northern Ireland programme for the control and eradication of Mycobacterium bovis. Vet Microbiol. 2006;112(2-4): 231-237.

8. More SJ, Good M. The tuberculosis eradication programme in Ireland: a review of scientific and policy advances since 1988. Vet Microbiol. 2006;112(2-4):239-251.

9. Reynolds D. A review of tuberculosis science and policy in Great Britain. Vet Microbiol. 2006;112(2-4):119-126.

10. Corner LA. The role of wild animal populations in the epidemiology of tuberculosis in domestic animals: how to assess the risk. Vet Microbiol. 2006;112(2-4):303-312.

11. Delahay RJ, Smith GC, Barlow AM, et al. Bovine tuberculosis infection in wild mammals in the South-West region of England: a survey of prevalence and a semi-quantitative assessment of the relative risks to cattle. Vet J. 2007;173(2):287-301.

12. Gortazar C, Vicente J, Boadella M, et al. Progress in the control of bovine tuberculosis in Spanish wildlife. Vet Microbiol. 2011;151(1-2): $170-178$.

13. Fitzgerald SD, Kaneene JB. Wildlife reservoirs of bovine tuberculosis worldwide: hosts, pathology, surveillance, and control. Vet Pathol. 2013;50(3):488-499.

14. Muirhead RH, Gallagher J, Burns KJ. Tuberculosis in wild badgers in Gloucestershire: epidemiology. Vet Rec. 1974;95(24):552-555.

15. Noonan N, Sheane W, Harper L, Ryan P. Wildlife as a possible reservoir for bovine tuberculosis. Ir Vet J. 1975;29:1.

16. Balseiro A, Gonzalez-Quiros P, Rodriguez O, et al. Spatial relationships between Eurasian badgers (Meles meles) and cattle infected with Mycobacterium bovis in Northern Spain. Vet J. 2013;197(3): 739-745.

17. Payne A, Boschiroli ML, Gueneau E, et al. Bovine tuberculosis in "Eurasian" badgers (Meles meles) in France. Eur $J$ Wildlife Res. 2013;59(3):331-339.

18. Eves JA. Impact of badger removal on bovine tuberculosis in east County Offaly. Ir Vet J. 1999;52(4):199-203.

19. Donnelly CA, Woodroffe R, Cox DR, et al. Impact of localized badger culling on tuberculosis incidence in British cattle. Nature. 2003;426(6968):834-837.

20. Griffin JM, More SJ, Clegg TA, et al. Tuberculosis in cattle: the results of the four-area project. Ir Vet J. 2005;58(11):629-636.

21. Donnelly CA, Woodroffe R, Cox DR, et al. Positive and negative effects of widespread badger culling on tuberculosis in cattle. Nature. 2006;439(7078):843-846.

22. Furphy C, Costello E, Murphy D, Corner LA, Gormley E. DNA Typing of Mycobacterium bovis Isolates from Badgers (Meles meles) Culled from Areas in Ireland with Different Levels of Tuberculosis Prevalence. Vet Med Intl. 2012;2012:742478.

23. Murphy D, Gormley E, Costello E, O’Meara D, Corner LA. The prevalence and distribution of Mycobacterium bovis infection in European badgers (Meles meles) as determined by enhanced post mortem examination and bacteriological culture. Res Vet Sci. 2010; 88(1): $1-5$.

24. Murphy D, Gormley E, Collins DM, et al. Tuberculosis in cattle herds are sentinels for Mycobacterium bovis infection in European badgers (Meles meles): the Irish Greenfield Study. Vet Microbiol. 2011;151(1-2):120-125.
25. Bourne FJ, Donnelly C, Cox D, et al. Bovine TB: The Scientific Evidence, a Science Base for a Sustainable Policy to Control TB in Cattle, an Epidemiological Investigation into Bovine Tuberculosis. Final Report of the Independent Scientific Group on Cattle TB. London, UK: Department for Environment, Food and Rural Affairs; 2007.

26. Costello E, O'Grady D, Flynn O, et al. Study of restriction fragment length polymorphism analysis and spoligotyping for epidemiological investigation of Mycobacterium bovis infection. J Clin Microbiol. 1999;37(10):3217-3222.

27. Olea-Popelka FJ, Flynn O, Costello E, et al. Spatial relationship between Mycobacterium bovis strains in cattle and badgers in four areas in Ireland. Prev Vet Med. 2005;71(1-2):57-70.

28. Gormley E, Collins JD. The development of wildlife control strategies for eradication of tuberculosis in cattle in Ireland. Tuber Lung Dis. 2000;80(4-5):229-236.

29. Rogers LM, Forrester GJ, Wilson GJ, Yarnell RW, Cheeseman CL. The role of setts in badger (Meles meles) group size, breeding success and status of TB (Mycobacterium bovis). Journal of Zoology. 2003;260(2):209-215.

30. Rogers LM, Cheeseman CL, Mallinson PJ, CliftonHadley R. The demography of a high-density badger (Meles meles) population in the west of England. Journal of Zoology. 1997;242(4):705-728.

31. Sleeman DP, Mulcahy MF. Behaviour of Irish Badgers in Relation to Bovine Tuberculosis. Dublin: Royal Irish Academy; 1993.

32. Neal E, Cheeseman C. Badgers. London: Poyser; 1996.

33. Cleary GP, Corner LAL, O'Keeffe J, Marples NM. The diet of the badger Meles meles in the Republic of Ireland. Mammalian Biology. 2009;74(6):438-445.

34. Kruuk H, Parish T, Brown CAJ, Carrera J. The use of pasture by the European badger (Meles meles). Journal of Applied Ecology. 1979; 16:453-459.

35. Garnett BT, Delahay RJ, RoperTJ. Use of cattle farm resources by badgers (Meles meles) and risk of bovine tuberculosis (Mycobacterium bovis) transmission to cattle. Proc Biol Sci. 2002;269(1499):1487-1491.

36. Gallagher J, Muirhead RH, Burn KJ. Tuberculosis in wild badgers (Meles meles) in Gloucestershire: pathology. Vet Rec. 1976;98(1):9-14.

37. Gallagher J, Clifton-Hadley RS. Tuberculosis in badgers; a review of the disease and its significance for other animals. Res Vet Sci. 2000;69(3):203-217.

38. Jenkins HE, Morrison WI, Cox DR, et al. The prevalence, distribution and severity of detectable pathological lesions in badgers naturally infected with Mycobacterium bovis. Epidemiol Infect. 2008;136(10):1350-1361.

39. Corner LA, O’Meara D, Costello E, Lesellier S, Gormley E. The distribution of Mycobacterium bovis infection in naturally infected badgers. Vet J. 2012;194(2):166-172.

40. Orme IM, Cooper AM. Cytokine/chemokine cascades in immunity to tuberculosis. Immunol Today. 1999;20(7):307-312.

41. Gavier-Widen D, Chambers MA, Palmer N, Newell DG, Hewinson RG. Pathology of natural Mycobacterium bovis infection in European badgers (Meles meles) and its relationship with bacterial excretion. Vet Rec. 2001;148(10):299-304.

42. Cheeseman CL, Wilesmith JW, Stuart FA. Tuberculosis: the disease and its epidemiology in the badger, a review. Epidemiol Infect. 1989;103(1):113-125.

43. Corner LA, Gormley E. Mycobacterial infections in multiple species: implications for diagnosis and control. Vet J. 2012;191(2):141-142.

44. Gallagher J. The Natural History of Spontaneous Tuberculosis in Wild Badgers. London: University of London; 1998.

45. Dolan LA. Badgers and Bovine Tuberculosis in Ireland: A review. In: Hayden JT, editor. The Badger. Dublin: Royal Irish Academy. 1993:108-116.

46. Neill SD, O’Brien JJ, Hanna J. A mathematical model for Mycobacterium bovis excretion from tuberculous cattle. Vet Microbiol. 1991;28(1):103-109.

47. Chambers MA, Williams A, Gavier-Widen D, et al. A guinea pig model of low-dose Mycobacterium bovis aerogenic infection. Vet Microbiol. 2001;80(3):213-226. 
48. Corner LA, Costello E, Lesellier S, O'Meara D, Sleeman DP, Gormley E. Experimental tuberculosis in the European badger (Meles meles) after endobronchial inoculation of Mycobacterium bovis: I. Pathology and bacteriology. Res Vet Sci. 2007;83(1):53-62.

49. Cheeseman CL, Jones GW, Gallagher J, Mallinson PJ. The PopulationStructure, Density and Prevalence of Tuberculosis (Mycobacterium bovis) in Badgers (Meles meles) from 4 Areas in Southwest England. J Appl Ecol. 1981;18(3):795-804.

50. Roy CJ, Milton DK. Airborne transmission of communicable infection - the elusive pathway. N Engl J Med. 2004;350(17): 1710-1712.

51. Donaldson AI. Factors influencing the dispersal, survival and deposition of airborne pathogens of farm animals. Veterinary Bulletin. 1978;48:83-94.

52. Marthi B, Fieland VP, Walter M, Seidler RJ. Survival of bacteria during aerosolization. Appl Environ Microbiol. 1990;56(11):3463-3467.

53. Walter MV, Marthi B, Fieland VP, Ganio LM. Effect of aerosolization on subsequent bacterial survival. Appl Environ Microbiol. 1990;56(11):3468-3472.

54. Cox HH, Deshusses MA. Biological waste air treatment in biotrickling filters. Curr Opin Biotechnol. 1998;9(3):256-262.

55. Nardell EA. Catching droplet nuclei: toward a better understanding of tuberculosis transmission. Am J Respir Crit Care Med. 2004;169(5): $553-554$.

56. Radunz B. Surveillance and risk management during the latter stages of eradication: experiences from Australia. Vet Microbiol. 2006;112(2-4):283-290.

57. Tweddle NE, Livingstone P. Bovine tuberculosis control and eradication programs in Australia and New Zealand. Vet Microbiol. 1994;40(1-2):23-39.

58. Caley P, Hickling GJ, Cowan PE, Pfeiffer DU. Effects of sustained control of brushtail possums on levels of Mycobacterium bovis infection in cattle and brushtail possum populations from Hohotaka, New Zealand. N Z Vet J. 1999;47(4):133-142.

59. Buddle B, de Lisle G, Griffin J, Hutchings S. Epidemiology, diagnostics, and management of tuberculosis in domestic cattle and deer in New Zealand in the face of a wildlife reservoir. $N Z$ Vet J. 2014:1-23.

60. Carstensen M, Doncarlos MW. Preventing the establishment of a wildlife disease reservoir: a case study of bovine tuberculosis in wild deer in Minnesota, USA. Vet Med Int. 2011;2011:413240.

61. Griffin JM, Williams DH, Kelly GE, et al. The impact of badger removal on the control of tuberculosis in cattle herds in Ireland. Prev Vet Med. 2005;67(4):237-266.

62. Olea-Popelka FJ, Fitzgerald P, White P, et al. Targeted badger removal and the subsequent risk of bovine tuberculosis in cattle herds in county Laois, Ireland. Prev Vet Med. 2009;88(3):178-184.

63. Byrne AW, O'Keeffe J, Sleeman DP, Davenport J, Martin SW. Impact of culling on relative abundance of the European badger (Meles meles) in Ireland. Eur J Wildlife Res. 2013;59(1):25-37.

64. Sleeman DP, Davenport J, More S, et al. How many Eurasian badgers Meles meles L. are there in the Republic of Ireland? Eur J Wildl Res. 2009;55:333-344

65. Sheridan M. Progress in tuberculosis eradication in Ireland. Vet Microbiol. 2011;151(1-2):160-169.

66. More SJ, Clegg TA, McGrath G, Collins JD, Corner LA, Gormley E. Does reactive badger culling lead to an increase in tuberculosis in cattle? Vet Rec. 2007;161(6):208-209.

67. Kelly GE, Condon J, More SJ, Dolan L, Higgins I, Eves J. A long-term observational study of the impact of badger removal on herd restrictions due to bovine TB in the Irish midlands during 1989-2004. Epidemiol Infect. 2008;136(10):1362-1373.

68. Sheridan M, Good M, More SJ, Gormley E. The impact of an integrated wildlife and bovine tuberculosis eradication program in Ireland. In Thoen CO, Steele JH, Kaneene JB. Zoonotic Tuberculosis: Mycobacterium bovis and Other Pathogenic Mycobacteria. 3rd ed: Wiley Blackwell; 2014:323-340.
69. Bourne FJ, Donnelly CA, Cox DR, et al. TB policy and the badger culling trials. Vet Rec. 2006;158(19):671-672.

70. Department for Environment, Food \& Rural Affairs. The Government's Policy on Bovine TB and Badger Control in England; 2011. Available from: https://http://www.gov.uk/government/uploads/system/uploads/ attachment_data/file/69463/pb13691-bovinetb-policy-statement.pdf. Accessed September 5, 2014.

71. Jenkins HE, Woodroffe R, Donnelly CA. The effects of annual widespread badger culls on cattle tuberculosis following the cessation of culling. Int J Infect Dis. 2008;12(5):457-465.

72. Ward AI, Judge J, Delahay RJ. Farm husbandry and badger behaviour: opportunities to manage badger to cattle transmission of Mycobacterium bovis? Prev Vet Med. 2010;93(1):2-10.

73. Judge J, McDonald RA, Walker N, Delahay RJ. Effectiveness of Biosecurity Measures in Preventing Badger Visits to Farm Buildings. PloS One. 2011;6(12):e28941.

74. Benham PF, Broom DM. Interactions between cattle and badgers at pasture with reference to bovine tuberculosis transmission. Br Vet J. 1989;145(3):226-241.

75. Bohm M, Hutchings MR, White PC. Contact networks in a wildlifelivestock host community: identifying high-risk individuals in the transmission of bovine TB among badgers and cattle. PloS One. 2009;4(4):e5016.

76. Benham PF, Broom DM. Responses of dairy cows to badger urine and faeces on pasture with reference to bovine tuberculosis transmission. Br Vet J. 1991;147(6):517-532.

77. Corner LA, Costello E, Lesellier S, O’Meara D, Gormley E. Vaccination of European badgers (Meles meles) with BCG by the subcutaneous and mucosal routes induces protective immunity against endobronchial challenge with Mycobacterium bovis. Tuberculosis (Edinb). 2008;88(6):601-609.

78. Lesellier S, Corner L, Costello E, et al. Immunological responses and protective immunity in BCG vaccinated badgers following endobronchial infection with Mycobacterium bovis. Vaccine. 2009;27(3): 402-409.

79. Chambers MA, Rogers F, Delahay RJ, et al. Bacillus Calmette-Guerin vaccination reduces the severity and progression of tuberculosis in badgers. Proc Biol Sci. 2011;278(1713):1913-1920.

80. Carter SP, Chambers MA, Rushton SP, et al. BCG vaccination reduces risk of tuberculosis infection in vaccinated badgers and unvaccinated badger cubs. PloS One. 2012;7(12):e49833.

81. Corner LA, Costello E, O’Meara D, et al. Oral vaccination of badgers (Meles meles) with BCG and protective immunity against endobronchial challenge with Mycobacterium bovis. Vaccine. 2010;28(38): $6265-6272$.

82. Lesellier S, Palmer S, Dalley DJ, et al. The safety and immunogenicity of Bacillus Calmette-Guerin (BCG) vaccine in European badgers (Meles meles). Vet Immunol Immunopathol. 2006;112(1-2): 24-37

83. Tompkins DM, Ramsey DS, Cross ML, Aldwell FE, de Lisle GW, Buddle BM. Oral vaccination reduces the incidence of tuberculosis in freeliving brushtail possums. Proc Biol Sci. 2009;276(1669):2987-2995.

84. dardni.gov.uk [homepage on the Internet]. Test and vaccinate or remove (TVR) wildlife intervention research; 2012. Available from: http://www.dardni.gov.uk/test-and-vaccinate-or-remove.htm. Accessed May 17, 2014

85. Aznar I, McGrath G, Murphy D, et al. Trial design to estimate the effect of vaccination on tuberculosis incidence in badgers. Vet Microbiol. 2011;151(1-2):104-111.

86. Department for Environment, Food \& Rural Affairs. Reducing bovine tuberculosis (bovine TB) [webpage on the Internet]. Available from: https:/www.gov.uk/government/policies/reducing-bovine-tuberculosis/ supporting-pages/badger-vaccination. Accessed November 11, 2014.

87. Department for Environment, Food \& Rural Affairs. Badger Edge Vaccination Scheme; 2014. Available from: http://www.parliament. uk/documents/commons-vote-office/September 2014/2 September/2DEFRA-BovineTB.pdf. Accessed October 24, 2014. 
88. Kelly DJ, Corner LAL, Gormley E, et al. Evaluation of attractant flavours for use in oral vaccine baits for badgers (Meles meles). Eur J Wildlife Res. 2011;57(4):767-774.

89. Wilson GJ, Carter SP, Delahay RJ. Advances and prospects for management of TB transmission between badgers and cattle. Vet Microbiol. 2011;151(1-2):43-50.

90. wales.gov.uk [homepage on the Internet]. Welsh Government. Intensive Action Area; 2014. Available from: http://wales.gov.uk/topics/ environmentcountryside/ahw/disease/bovinetuberculosis/intensiveaction-area/?lang=en. Accessed October 24, 2014.

91. Buddle BM, Wedlock DN, Denis M, Vordermeier HM, Hewinson RG. Update on vaccination of cattle and wildlife populations against tuberculosis. Vet Microbiol. 2011;151(1-2):14-22.

92. Ameni G, Vordermeier M, Aseffa A, Young DB, Hewinson RG. Field evaluation of the efficacy of Mycobacterium bovis bacillus CalmetteGuerin against bovine tuberculosis in neonatal calves in Ethiopia. Clin Vaccine Immunol. 2010;17(10):1533-1538.

93. Lopez-Valencia G, Renteria-Evangelista T, Williams Jde J, Licea-Navarro A, Mora-Valle Ade L, Medina-Basulto G. Field evaluation of the protective efficacy of Mycobacterium bovis BCG vaccine against bovine tuberculosis. Res Vet Sci. 2010;88(1):44-49.

94. Jones GJ, Gordon SV, Hewinson RG, Vordermeier HM. Screening of Predicted Secreted Antigens from Mycobacterium bovis Reveals the Immunodominance of the ESAT-6 Protein Family. Infect Immun. 2010;78(3):1326-1332.
95. Vordermeier M, Gordon SV, Hewinson AR. Antigen Mining to Define Mycobacterium bovis Antigens for the Differential Diagnosis of Vaccinated and Infected Animals: A VLA Perspective. Transboundary Emerg Dis. 2009;56(6-7):240-247.

96. Vordermeier M, Gordon SV, Hewinson RG. Mycobacterium bovis antigens for the differential diagnosis of vaccinated and infected cattle. Vet Microbiol. 2011;151(1-2):8-13.

97. Vordermeier M, Jones GJ, Whelan AO. DIVA reagents for bovine tuberculosis vaccines in cattle. Expert Rev Vaccines. 2011;10(7): 1083-1091.

98. Sidders B, Pirson C, Hogarth PJ, et al. Screening of highly expressed mycobacterial genes identifies Rv3615c as a useful differential diagnostic antigen for the Mycobacterium tuberculosis complex. Infect Immun. 2008;76(9):3932-3939.

99. EFSA Panel on Animal Health and Welfare (AHAW). Scientific Opinion on field trials for bovine tuberculosis vaccination. EFSA Journal. 2013;11:3475.

100. tbfree.rog.nz [homepage on the Internet]. TBfree New Zealand. Animal Health Board Annual Report 2012-2013. Available from: http://www. tbfree.org.nz/Portals/0/AHB\%20Annual\%20Report\%20E-book\%20 2012-13final.pdf. Accessed October 24, 2014.

101. Robinson PA, Corner LA, Courcier EA, et al. BCG vaccination against tuberculosis in European badgers (Meles meles): a review. Comp Immunol Microbiol Infect Dis. 2012;35(4):277-287.
Veterinary Medicine: Research and Reports

\section{Publish your work in this journal}

Veterinary Medicine: Research and Reports is an international, peer-reviewed, open access journal publishing original research, case reports, editorials, reviews and commentaries on all areas of veterinary medicine. The manuscript management system is completely online and includes a very quick and fair peer-review system.

\section{Dovepress}

Visit http://www.dovepress.com/testimonials.php to read real quotes from published authors. 